\title{
Chapter 9 \\ Integration of Formal, Non-formal and Informal Learning Through MOOCs
}

\author{
Hyunjin Cha and Hyo-Jeong So
}

\begin{abstract}
Since the first appearance of MOOCs in the higher education context, MOOCs have been integrated and transformed into several learning variations. In particular, by integrating formal traditional courses with informal learning approaches, MOOCs have been expanding the position as a learning platform to provide students with diverse learning experiences delivered through blended learning modalities. This chapter aims to discuss how MOOCs have been integrated into higher education contexts to blend formal, non-formal and informal learning experiences. An integration framework suggested in this chapter is based on two factors, namely credit recognition and online learning that lead to three types of MOOC-integrated learning experiences: Type I-formal MOOC learning, Type II-formal blended MOOC learning, and Type III-non-formal/informal MOOC learning. Based on this framework, we mainly illustrate three integration approaches, namely blended learning, flipped learning, and non-formal/informal learning experiences, with relevant research studies. The chapter concludes with some suggestions for research directions that can inform future research on integrating formal and non-formal/informal learning experiences through MOOCs in higher education.
\end{abstract}

Keywords MOOCs $\cdot$ Flipped learning $\cdot$ Blended learning $\cdot$ Formal learning $\cdot$ Informal learning $\cdot$ Non-formal learning

\footnotetext{
H. Cha

SoonChunHyang University, \#6524, 22 Soonchunhyang-ro, Shinchang-myeon, Asan-si, Chungcheongnam-do 31538, Republic of Korea

e-mail: lois6934@hanmail.net
}

\section{H.-J. So $(\bowtie)$}

Ewha Womans University, Education Building A \#405, 52, Ewhayeodae-gil, Seodaemun-gu, Seoul 03760, Republic of Korea e-mail: hyojeongso@ewha.ac.kr 


\subsection{Introduction}

Scholars have pointed out the problems of a knowledge-transmission paradigm of education rooted in industrialism, such as uniform teaching and learning, teachercentric methods, standardized assessment, and learning by acquisition (Halverson \& Collins, 2009). Higher education intuitions have explored new methods of teaching and learning with the integration of technologies to move away from knowledgetransmission to knowledge creation, and to provide students with more flexible learning opportunities through online technologies. The growth of online learning in the higher education sector has occurred through blending various learning approaches. Massive Open Online Course (MOOC) is one of the emerging approaches in higher education that leverages the openness of learning content for massive learners for the delivery of content and instruction. For the past decade, MOOCs have been transformed into several variations since the first appearance in the higher education sector. Brown (2018) suggests that MOOCs have gone through three waves. During the first wave, MOOCs were mainly used for marketing purposes to increase the institution's visibility and to recruit more students. The second wave is to use MOOCs for lifelong learning, propelled by large-scale MOOC projects at a national level and a cross-institutional level. The third wave is to use MOOCs for credit recognition and continuing professional development pathways.

Despite such increasing variations of MOOCs in the higher education landscape, a little framework is available to unpack mechanisms that blend various learning experiences. In MOOCs, as portions of learning experiences are delivered partly through online modalities, various integrations can happen, affecting what students learn online and face-to-face. Further, MOOCs have been increasingly positioned as a platform to integrate formal traditional courses with informal learning experiences. Given this nature of variations in MOOCs, this chapter aims to present and discuss various ways of integrating formal and informal learning experiences through MOOCs. This chapter is structured to firstly provide theoretical understandings of various MOOCs in the higher education sector, and then to present the integration framework with discussions of respective research studies. In the integration framework, we mainly discuss three approaches: blended learning, flipped learning, and non-formal/informal learning. The chapter concludes with some suggestions for research directions that can inform future research on integrating formal and informal learning experiences through MOOCs in higher education.

\subsection{Theoretical Foundation}

\subsubsection{MOOCs: Concepts and Features}

MOOCs have provided innovative open learning environments since the term was first introduced in 2008 (Akgül, 2018; Littlejohn \& Milligan, 2015). MOOCs have 
been derived from distance education but have more distinctive features as courses are completely online, free and open to anyone, and available to massive audiences (Atiaja \& Gueerero, 2016; Iniesto, McAndrew, Minocha, \& Coughlan, 2017). MOOCs were originated from the Open Educational Resources (OER) movement, which is a philosophy to offer educational opportunities to all through free content and courses (Atiaja \& Guerrero, 2016). The original notion of this innovative approach is for open access to learning. Moreover, the socio-cultural trends accelerated through the development of web 2.0 technology and social networks promoted the emergence of connectivism as a new pedagogical phenomenon that emphasizes participating and interacting, sharing ideas, and developing new knowledge through the continual improvement of knowledge among learners on the open learning platforms.

MOOCs as the innovative educational stream have attracted much public attention since diverse groups of learners can benefit from open access with a formal educational structure, free or low cost, flexible learning process with preferred pace and place, social learning opportunities, and even earning certificates and credits from prestigious universities (Iniesto et al., 2017). From learners' perspectives, there are a variety of motivations to take MOOC courses: to gain better understanding about a certain subject or topic, to explore a specific field of interest, to participate in social interactions, and to have fun and enjoyable experiences without any expectation of achievement and completion (Belanger \& Thornton, 2013).

MOOCs have many advantages over traditional brick-and-mortar university models. First, MOOCs provide massive and diverse learners from all over the world with an opportunity to access open, free, and high-quality learning content (Abdelrahman, 2016). Second, MOOCs provide individual learners with an opportunity to personalize their learning in terms of topics, time, place, and methods (Morris, 2014). MOOC learners have different learning objectives and plan to utilize online courses according to their personal needs. In MOOCs, while some students aim to achieve a certificate by studying the entire weeks of content with assignments, other students plan to study a specific element and content that they are interested in. To support such different student needs, MOOCs have taken an open approach to increase the availability of on-demand course videos and flexible schedules (Lapworth, 2018). Third, at an institutional level, MOOCs can be a strategic driver to increase student recruitments through the increased visibility of institutions and can promote the accessibility of lifelong learning opportunities with flexible pathways to international alliances (Brown, 2018). Universities can expand curriculums and opportunities with cross-cultural knowledge and friendship around the globe for their students. Finally, MOOCs have recently evolved to use learning analytics to better identify student profiles and learning paths. As big data and intelligent technologies are advancing, learners' self-regulation can be promoted through the automatic tracking of the frequency and patterns of learner engagement in MOOCs (Cha \& Park, 2019). 


\subsubsection{Comparison of Traditional, Blended, and Flipped Learning}

For a clear conceptualization of integrating MOOCs in higher education, we firstly contrast the characteristics (a) traditional instruction, (b) blended learning, and (c) flipped learning. First, traditional instruction can be described as a direct instruction approach, where an instructor mainly delivers a face-to-face lecture in a classroom. Students learn mainly through textbooks, lectures, and assignments in the classroom setting. It is important to acknowledge that direct instruction or an instructor-led lecture is not in itself good or bad. There is sufficient evidence that direct instruction is effective for delivering declarative knowledge to learners and for reducing cognitive load (Kirschner, Sweller, \& Clark, 2006). Rather, the critics of direct instruction are associated with the lack of time devoted to high-order cognitive skills, such as applying, analyzing, and evaluating, since most of the class time is devoted to transmitting content knowledge in an instructor-centric mode (Kuhn, 2007).

Second, blended learning refers to the combination of face-to-face instruction and computer-mediated instruction (Graham, 2006). The term blended learning is widely used both in research and practices. Howecer, it is challenging to distinguish flipped learning and blended learning since both approaches involve online and faceto-face (F2F) learning activities. Although flipped learning is perceived as a form of blending online and offline learning (Strayer, 2012), some scholars have argued that flipped learning differs from blended learning by clearly separating online and offline activities (Hwang \& Lai, 2017). For instance, Thai, Wever, and Valcke (2017) compare a flipped classroom with other similar learning approaches that combine face-to-face and online learning components. Table 9.1 shows that the key difference between blended learning and the flipped classroom is reversing the order of online and face-to-face settings in presenting lectures and guiding questions, as well as in the immediacy of a feedback loop. That is, in the flipped classroom, lectures are delivered online, and guiding questions that scaffold students' deeper understanding about knowledge acquired from the lecture videos occur in a face-to-face mode with immediate feedback.

Lastly, it is possible that in-class teaching of flipped learning remains an instructorcentered approach when instructors focus mainly on reviewing the content that learners have already learned through lecture videos before class. With that, the Flipped

Table 9.1 Comparison of the main characteristics of various learning approaches (Thai et al., 2017)

\begin{tabular}{l|l|l|l|l}
\hline & Traditional & e-learning & Blended learning conditions \\
\cline { 4 - 5 } & learning & & Blended learning & $\begin{array}{l}\text { Flipped } \\
\text { classroom }\end{array}$ \\
\hline Lecture & F2F & Online & F2F & Online \\
\hline $\begin{array}{l}\text { Guiding } \\
\text { questions }\end{array}$ & F2F & Online & Online & F2F \\
\hline Feedback & F2F immediate & Online delayed & Online delayed & F2F immediate \\
\hline
\end{tabular}


Learning Network (FLN) differentiates the concepts of flipped classroom and flipped learning. Flipping a class is a method of presenting lectures and supplementary materials in advance before class, as some instructors have already done in the past. The FLN suggests that although flipping a class can lead to flipped learning, it does not necessarily do so. For the proper implementation of flipped learning, the FLN suggests that instructors must incorporate the four pillars of F-L-I-PTM, namely flexible environment, learning culture, intentional content, and a professional educator (Bergmann \& Sams, 2014). In this study, we use the term flipped learning, following the definition by FLN, to refer to "a pedagogical approach in which direct instruction moves from the group learning space to the individual learning space, and the resulting group space is transformed into a dynamic, interactive learning environment where the educator guides students as they apply concepts and engage creatively in the subject matter" (Flipped Learning Network, 2014, p. 1). Flipped learning advocates learning experiences that engage learners in cognitive processes demanded in the real-world context. By moving much of the abstract learning outside of class and bringing in more practical activities into the class, this sequence of learning can better facilitate student engagement in high-level cognitive activities and knowledge integration.

\subsection{Integration Framework}

Credit recognition is an important consideration of MOOCs in higher education. Sandeen (2013) suggests that higher education institutions are entering the era of the hybrid MOOC called "MOOC 3.0 or hMOOC", which indicates the increasing trend of integrating MOOCs into traditional academic programs or courses for academic credits. However, Chamberlin and Parish (2011) contend that students who receive credits from MOOCs tend to receive more benefits such as additional meetings and activities with the facilitator than non-credit students. If students choose to enroll in MOOCs due to the advantage of the flexible learning environment to earn academic credits, their behavior may not be fully encouraged by intrinsic motivation, but by external incentives to some extent. Hence, it is necessary to distinguish two types of MOOCs: (a) formal, certification-oriented participation in MOOCs where learning is primarily centered on receiving credits from MOOCs and (b) non-formal, professional development-oriented participation in MOOCs where learning is centered on the utilization of knowledge in real-world contexts.

Based on the understanding of different learning approaches, we propose a framework that integrates formal and informal learning experiences through MOOCs. While there are various ways to conceptualize formal, non-formal and informal learning, we adopt the definitions by OECD (2010):

- Formal learning: learning that occurs in an organized structured environment and is explicitly designated as learning in terms of learning objectives, time, or learning support. 
- Informal learning: learning that results from daily activities related to work, family, or leisure. It is not organized or structured in terms of learning objectives, time, or learning support.

- Non-formal learning: learning which is embedded in planned activities not explicitly designated as learning in terms of learning objectives, time, or learning support.

Our proposed MOOC integration framework is based on two factors, namely credit recognition and online learning. As shown in Fig. 9.1, this leads to three types of MOOC-integrated learning experiences. Type I is formal MOOC learning that refers to a learning approach where learners take a MOOC without any faceto-face instruction and receive academic credits. Type $\mathrm{I}$ is formal learning since learning experiences tend to be structured with an explicit goal to earn credits or certificates. Type II is formal blended MOOC learning where MOOCs are used to supplement or replace some portions of formal courses. Under this type, two combinations are possible depending on how and when MOOCs are used in the course structure: blended learning and flipped learning. As shown in Table 9.2, we adopt the framework by Thai et al. (2017) to differentiate blended learning and flipped learning. In blended learning, a lecture is delivered by instructors in a classroom in a face-to-face mode, and MOOCs are typically used as part of learning activities after F2F lectures. Flipped learning is a special form of blended learning where the primary delivery of instructional content is online via MOOCs and occurs in a remote location before classroom sessions. F2F in-class time is devoted to learning activities that aim to enhance the understanding of lecture content. Type III is non-formal or informal MOOC learning where learners use a MOOC without an intention to earn credits or certificates. The degree of structuring learning experiences determines non-formal

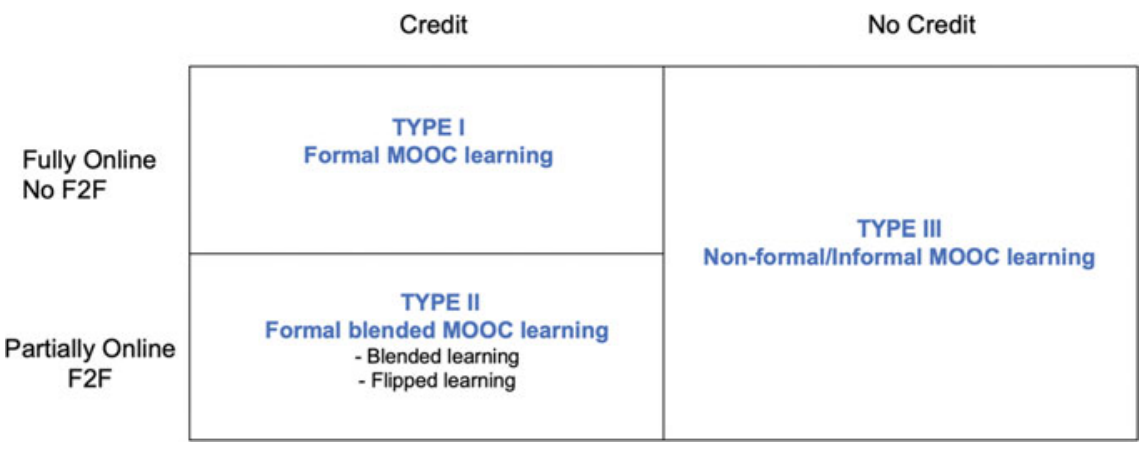

Fig. 9.1 MOOC integration framework

Table 9.2 Blended learning versus flipped learning

\begin{tabular}{l|l|l}
\hline & Lecture & Activities \\
\hline Flipped learning & Online & Face-to-face \\
\hline Blended learning & Face-to-face & Online \\
\hline
\end{tabular}


or informal learning experiences. Non-formal learning tends to be a more structured use of MOOCs, whereas informal learning with MOOCs can take place in a less structured way.

In the following section, we review and discuss how MOOCs have been used in various integration approaches. Type 1 (fully online MOOC) is not discussed here since this chapter is interested in incorporating different learning components such as the combination of online and offline learning or formal and informal learning experiences. Our review of the existing literature reveals that three integration approaches are often used in the higher education contexts: (1) integrating MOOCs in blended learning, (2) integrating MOOCs in flipped learning, and (3) integrating MOOCs in non-formal and informal learning.

\subsubsection{Integration Approach I: Integrating MOOCs in Blended Learning}

The first integration approach is to utilize MOOCs in blended learning to supplement and/or replace some segments of courses and learning contents in traditional formal learning (Bralić \& Divjak, 2016; National Research Council, 2012). Blended learning varies in concepts and models, depending on what form and mode are blended (Bryan \& Volchenkova, 2016). In this chapter, blended learning is defined as a hybrid form of learning that integrates MOOCs into traditional brick-and-mortar classrooms by taking the benefits of MOOCs in flexible ways. While some researchers (e.g., Bergmann \& Sams, 2012; Hung, Sun, \& Liu, 2018) used flipped learning in the same sense as blended learning, flipped learning has been studied with its own specific purposes and characteristics. Therefore, we classify flipped learning as a separate integration approach rather than blended learning. In this section, we discuss how MOOCs have been used in blended learning, which combines different learning modes (e.g., integration of online and offline, integration of MOOCs, and traditional classrooms).

Table 9.3 presents the summary of previous studies in the integration approach I. First, Griffiths, Mulhern, Spies, and Chingos (2015) conducted 10 case studies to address the issues of using MOOCs as a blended learning approach in traditional formal education. Faculty members from ten cases who voluntarily participated in the research were asked to integrate MOOCs into a variety of small, single-section courses. Depending on the case, instructors utilized MOOCs for replacing some segments of courses or enhancing the existing course materials. Their study found that there were no statistically significant differences in learning outcomes between the blended learning group and the traditional learning group. However, it was revealed that student satisfaction in the blended learning group was significantly lower than the traditional group since students preferred face-to-face interaction with instructors. In spite of low student satisfaction, Griffiths et al. (2015) found that faculty 


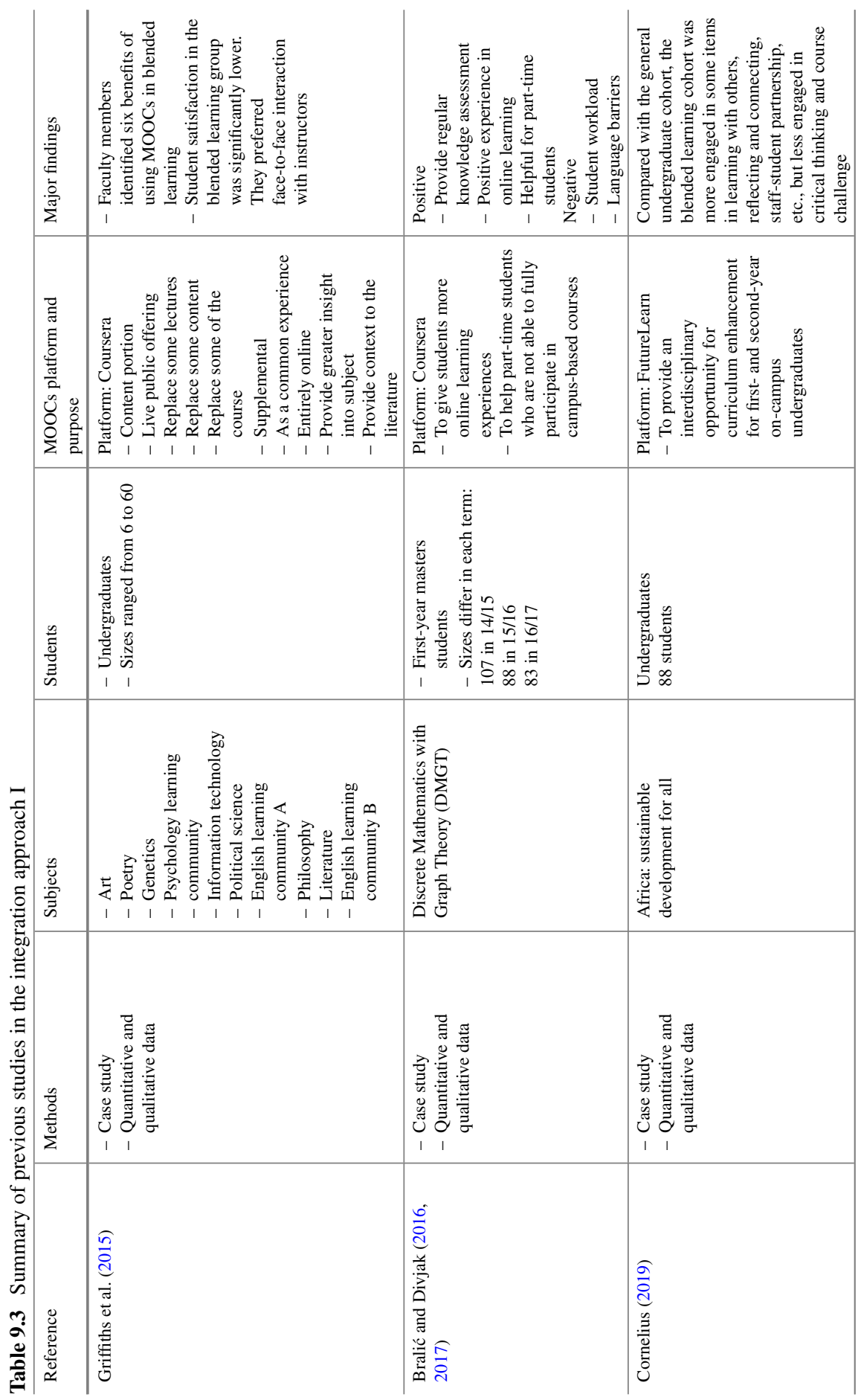


members identified six benefits of using MOOCs in blended learning: replacing lectures, augmenting secondary materials, filling gaps in expertise, exposing other types of teaching, reinforcing critical thinking, and improving how to learn online.

As another blended learning example, Bralić and Divajak (2016) conducted a case study about integrating MOOCs into a traditional course in a higher education context to demonstrate the qualitative effects on learning experiences of MOOCs as well as on learning achievements among part-time students through student's learning diary. The learning diary consisted of eight open questions to identify the benefits of learning experiences, effects on learning achievement for the part-time students, students' workload, and main challenges. The study revealed that the qualitative feedback and reflections from students were positive, especially in terms of self-paced learning and knowledge assessment on a regular basis. In particular, students recognized blended learning as a good approach taking the best of two modes since online learning was not highly motivating compared to face-to-face learning. However, they claimed that the main challenges were related to language problems and more time required to complete online MOOC contents.

Bralić and Divajak (2017) extended the study to trace student changes through three consecutive academic years and to see the effects of blended learning with MOOCs. They found that students who experienced blended learning wanted to take more MOOCs when they were given an option to choose either MOOCs or offline projects as assignments. Furthermore, they also reported that the former group who selected MOOCs as assignments achieved higher than those who selected an offline project as assignments. From the qualitative analysis, it was reported that most of the students had highly positive learning experiences with MOOCs such as opportunities with frequent evaluation and complementary learning experiences of what was taught in the offline class. The blended learning approach made students complete the online MOOC course and improved their self-efficacy. In addition, part-time students indicated that MOOCs helped them to adopt self-paced learning and met their individual needs.

Recently, Cornelius (2019) used a blended learning approach that replaced 6-week MOOC lectures, combining tutor-led tutorials and an independent study with additional materials. Quantitative and qualitative data were collected to analyze factors that might impact learner's engagement through MOOCs. The survey results showed that students from the blended learning approach were more engaged in the aspects of learning with others, reflecting and connecting, research and inquiry, staff-student partnership, and skills development compared to those in the offline campus approach.

In addition, the qualitative results demonstrated that students considered MOOCs as a flexible way of learning with a variety of resources. In particular, active and social learning was achieved through authentic contents and examples shared by peers in the discussions forum. Overall, incorporating MOOCs into traditional classrooms as a blended learning approach has many advantages: enhancing learning by making learners engaged in varied expertise and other styles of teaching and learning activities as well as enriching teaching and learning resources. The blended learning approach can also reinforce learning experience by providing the flexibility of 
teaching and learning, supporting diversity, and improving efficiency (Sharpe, Benfield, Roberts \& Francis, 2006). Indeed, students in the previous studies described self-control, flexibility, and diversity as positive features of the blended approach. However, as seen in low student satisfaction in some studies (e.g., Griffiths et al., 2015), it is crucial to consider how to employ MOOC contents in a blended context. That is, instructors should first consider how to integrate MOOCs into their formal education contexts since there are varied blended learning concepts and approaches.

\subsubsection{Integration Approach II: Integrating MOOCs in Flipped Learning}

The second and most prevalent integration is a flipped learning approach that integrates MOOCs into pre-class activities to promote student-centered learning during face-to-face in-class sessions (Hung et al., 2018). In general, flipped learning consists of pre-class, in-class, and after-class activities. Flipped learning originated from the idea of how instructors better utilize in-class time (Tucker, 2012). During the in-class time in flipped learning, it is crucial to have more interactions between peers and instructors through student-centered activities. To make the in-class time more interactive and student-centered, instructional video lectures are considered a powerful tool to replace teacher-led passive lectures. The concept behind flipped learning is to make students more actively engaged in learning, rather than passive participants in teacher-led lectures during the face-to-face in-class time (Bishop \& Verleger, 2013). In this respect, MOOCs courses and videos can also play an important role in helping instructors transform such instructor-centric lectures to student-centric learning experiences.

In this section, we consider previous studies that used MOOCs as a flipped learning approach in traditional brick-and-mortar university contexts. Table 9.4 presents the summary of previous studies in the integration approach II. Bruff, Fisher, McEwen, and Smith (2013) designed a course as a flipped learning approach by combining MOOC lectures and in-class activities such as supplementary reading and seminar in a traditional formal education setting. Ten weeks during the 14-week semester included MOOCs components so that the instructor was able to focus on in-class activities with interactive discussion and challenging materials. In this case study, students described the MOOC contents as effective, informative, and useful for selfpaced learning and thought that online lectures opened up a space for productive in-class discussions. The most obvious change was that students recognized the role of the instructor as a facilitator for in-class activities. However, they also pointed out some challenges such as the misalignment between online lectures and in-class components.

Ghadiri, Qayoumi, Junn, Hsu, and Sujitparapitaya (2013) conducted a pilot study that adopted flipped learning with three distinct activity phases: online outside-ofthe class with edX contents, in-class team-based learning, and after-class activities as described in Table 9.5. In the pilot study, despite student complaints about 
9 Integration of Formal, Non-formal and Informal Learning ...

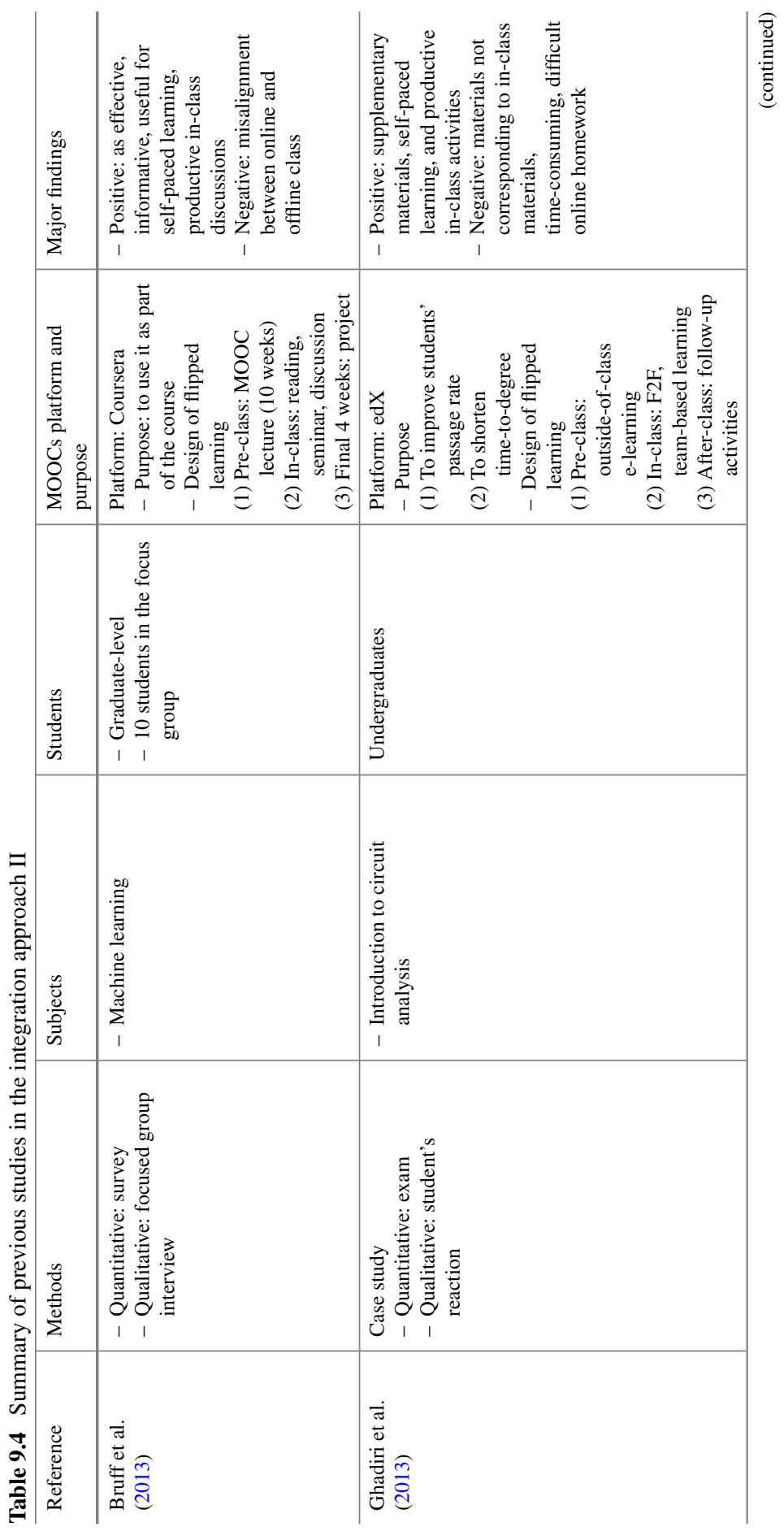




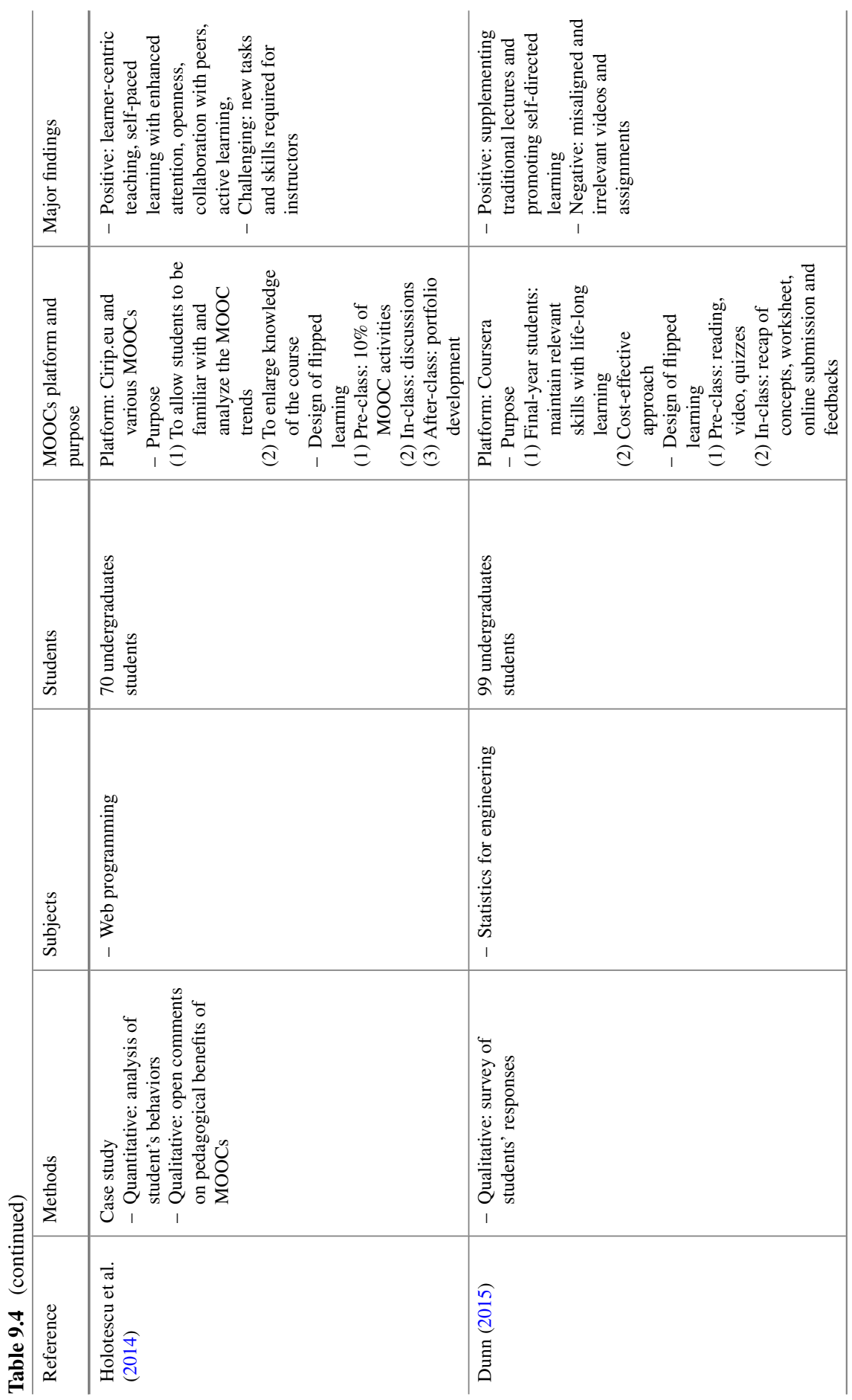


Table 9.5 Three distinct phases for the flipped learning approach (Ghadiri et al., 2013)

\begin{tabular}{|c|c|c|}
\hline $\begin{array}{l}\text { Step 1. online outside-of-the } \\
\text { class }\end{array}$ & $\begin{array}{l}\text { Step 2. in-class team-based } \\
\text { learning }\end{array}$ & Step 3. after-class activities \\
\hline $\begin{array}{l}\text { edX topical mini-lecture } \\
\text { videos }\end{array}$ & Mental ramp-up period & $\begin{array}{l}\text { Professor emails absent } \\
\text { students with class materials }\end{array}$ \\
\hline edX online textbook & In-class mini-review lecture & \multirow{6}{*}{$\begin{array}{l}\text { Optional, friday, one-hour, } \\
\text { F2F walk-in session }\end{array}$} \\
\hline edX problem sets & Group quiz & \\
\hline edX online lab experiments & Solution of group quiz & \\
\hline SJSU virtual discussion board & Individual quiz & \\
\hline \multirow[t]{2}{*}{$\begin{array}{l}\text { Assessment handout for the } \\
\text { next class session }\end{array}$} & $\begin{array}{l}\text { Solution to the individual } \\
\text { quiz }\end{array}$ & \\
\hline & Preview for next class session & \\
\hline
\end{tabular}

the extensive time and efforts required weekly with constant tests, the success rate of the course increased from $65 \%$ to $91 \%$. Qualitative data revealed that students perceived both positive and negative aspects. The positive aspects include accessing supplementary materials, self-paced learning, and productive in-class activities, whereas negative aspects include materials not corresponding to in-class materials, time-consuming activities, and online homework that is difficult, irrelevant, and too frequent.

Holotescu, Cretu, Grosseck, and Antoanela (2014) integrated different MOOCs, and the in-class time was devoted to discussion, exercise practices, and feedback on assignments. As the study was designed as a flipped learning approach, they evaluated MOOC participation and the pedagogical benefits of the flipped learning approach. The pedagogical benefits include learner-centric teaching, self-paced learning with enhanced attention, openness, collaboration with peers, active learning, etc. However, they emphasized that instructors must be equipped with new skills and tasks such as facilitating student discussions and dealing with complex course design. They suggested that instructors should find a suitable way of how to incorporate MOOCs into their teaching scenarios more effectively and efficiently. Similarly, Dunn (2015) implemented a flipped learning approach with Coursera as shown in Fig. 9.2 and discussed that the role of the instructor changed to a coordinator, collaborator, time-manager, and mentor, and flipped learning can promote group activities and peer learning.

Based on the literature discussed above in this section, we identified the common benefits of integrating MOOCs in flipped learning. First of all, productive in-class time is achieved by making students more actively engaged in discussions, projects, and exercise practices. Students have more opportunities to interact with their peers and/or instructors. Secondly, the role of instructors changed from a knowledge-giver to a knowledge facilitator. Thirdly, MOOCs play an effective role in replacing and supplementing traditional lectures and promoting self-directed learning. However, it was also revealed that MOOCs lectures and contents cannot completely replace in-class lectures because students reported misaligned and irrelevant videos and 


\begin{tabular}{|c|c|c|}
\hline Pre-class activities & In-class activities & After-class activities \\
\hline Reading & $\begin{array}{l}\text { Quick recap of } \\
\text { crucial concepts }\end{array}$ & $\begin{array}{l}\text { Review of group } \\
\text { worksheet and }\end{array}$ \\
\hline $\begin{array}{l}\text { MOOCs: watching } \\
\text { videos, answering } \\
\text { quizzes }\end{array}$ & $\begin{array}{l}\text { Group worksheet } \\
\text { and assessment }\end{array}$ & $\begin{array}{l}\text { comparing their } \\
\text { understanding }\end{array}$ \\
\hline Questionnaires & $\begin{array}{l}\text { Interaction with } \\
\text { peers }\end{array}$ & \\
\hline $\begin{array}{l}\text { Pre-class group } \\
\text { work }\end{array}$ & $\begin{array}{l}\text { Q\&A with the } \\
\text { instructor }\end{array}$ & \\
\hline
\end{tabular}

Fig. 9.2 Flipped learning approach with Coursera (Dunn, 2015)

assignments in MOOCs (e.g., Bruff et al., 2013; Ghadiri et al., 2013). In addition, students were not highly satisfied with MOOCs due to more efforts and time they should devote. In particular, Holotescu et al. (2014) emphasized that instructors are required with new course-redesign skills and pedagogical tasks as a facilitator. Therefore, it is crucial to consider how MOOC components can be integrated into traditional learning contexts more effectively and efficiently and how instructors can play a facilitator role during the in-class time to make flipped learning more successful.

\subsubsection{Integration Approach III: Integrating MOOCs in Non-formal and Informal Learning}

The final integration approach is to adopt MOOCs for non-formal or informal learning in higher education contexts. This approach reflects the original goal of OER and MOOCs, which is to benefit learners who would like to study with free, open, and flexible participation at their preferred pace and location. In addition, since many popular MOOCs are associated with world-class higher education (Alraimi, Zo, \& Ciganek, 2014), such disruptive potentials, which mean not only to create innovative opportunities but also to have potential threats (Kaltencher, Huesig, Hess, \& Dowling, 2013), can expand opportunities for non-formal and informal learning

OECD (2010) defines that informal learning is not structured or organized, whereas non-formal learning is associated with planned learning activities, but is not explicitly designed in terms of learning purposes, learning schedule, or learning supports. European Communities (2001) suggest that the differences between nonformal and informal learning lie in the structuredness in learning experiences and intention from learners' perspectives. Informal learning is more experienced-based learning, whereas non-formal learning is more intentional and structured. A common aspect of non-formal and informal learning is that learning does not necessarily lead 
to formal recognition such as degrees or certification. While some MOOC contents provide students with a structured syllabus, schedule, and certification, generally MOOCs do not force learners to such structured and certified learning experiences. Rather, MOOCs support learners to choose how, when, and in what ways they want to engage with flexible learning paths and goals. With the flexible nature of learning, MOOCs have attracted learners who have a variety of learning purposes and learning paths.

Table 9.6 summarizes previous studies related to the third integration approach. Earlier studies related to informal learning and non-formal learning through MOOCs focused on who studies, why and how learners study. For instance, Gillani and Eynon (2014) investigated the demographic characteristics of learners who were studying a Coursera-based MOOC. They found that the majority of learners were well-educated, young adults from developed countries, and had prior knowledge of the selected course. Among them, only $62.7 \%$ wanted to have a formal acknowledgment of their learning experiences. Similarly, Ho et al. (2015) investigated 68 courses from 2012 to 2014 through MOOCs by Harvard and MIT universities and found that $71 \%$ of leaners had a degree, $50 \%$ were younger than 30 years old, and $32 \%$ were from the USA. It was concluded that MOOCs might be utilized as a means for widening educational opportunities and for re-skilling and up-skilling purposes with a diverse range of goals (Sfiri, Pietkiewicz, \& Jansen, 2016). Such diversity in learning goals led to diverse learner's participation behaviors such as no-shows, observers, drop-ins, passive participants, and active participants (Hill, 2013).

The absence of instructors and pre-determined structure in non-formal and informal learning settings requires learners to self-regulate own learning experiences (Hood, Littlejohn, \& Milligan, 2015). Low completion rate is one of the main challenges that MOOCs faced (Jordan, 2014; Perna et al., 2014; Weller, 2014). Recently, researchers attempted to find factors that impact the completion of MOOCs and learner retention and to improve Self-Regulated Learning (SRL). For instance, Alraimi et al. (2014) found that perceived reputation and openness of MOOCs were stronger predictors for learner retention than perceived usefulness and enjoyment. On the other hand, Hone and Said (2016) focused on the factors related to MOOC features and user experiences that influenced learner retention in MOOCs and identified that perceived effectiveness of the MOOC contents affected learner retention. Another line of research into MOOC-integrated learning has focused on increasing the completion and retention rates by improving SRL strategies. Hood et al. (2015) found that learner's current contexts and learning purposes influenced their SRL in a MOOC about data science by Coursera. It was revealed that students who aimed to receive a Higher Education (HE) qualification had significantly higher SRL than those who were not studying for a HE qualification. Further, students with expertise in the data science area showed higher self-efficacy and meaningful learning approaches and strategies than those without expertise in the area.

Littlejohn, Hood, Milligan, and Mustain (2015) compared behaviors between learners with high and low self-reported SRL scores. They found that the intrinsic motivation and goals for high SRL-scored learners to develop knowledge and expertise in their workplace could lead to non-formal learning opportunities to select 


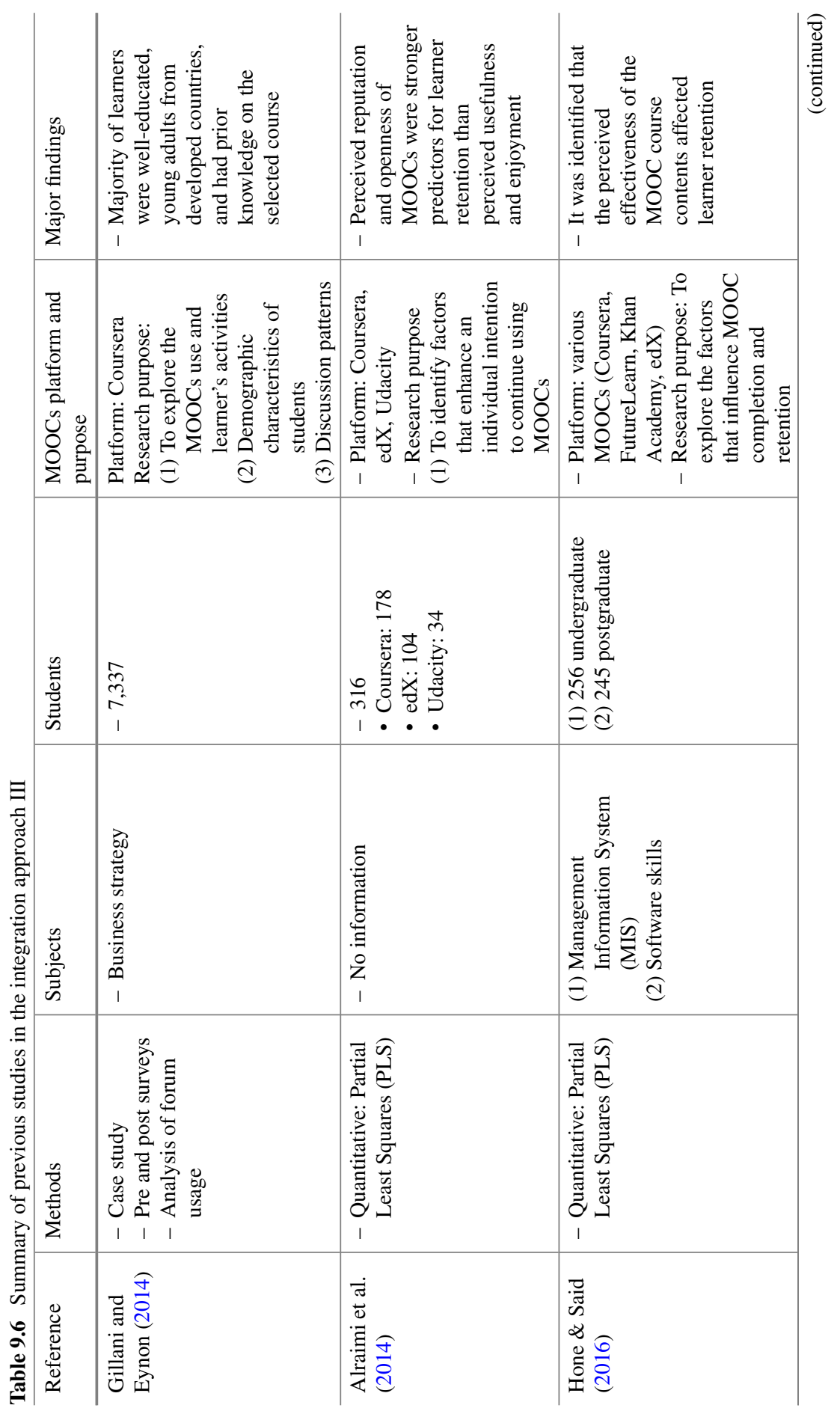


9 Integration of Formal, Non-formal and Informal Learning ...

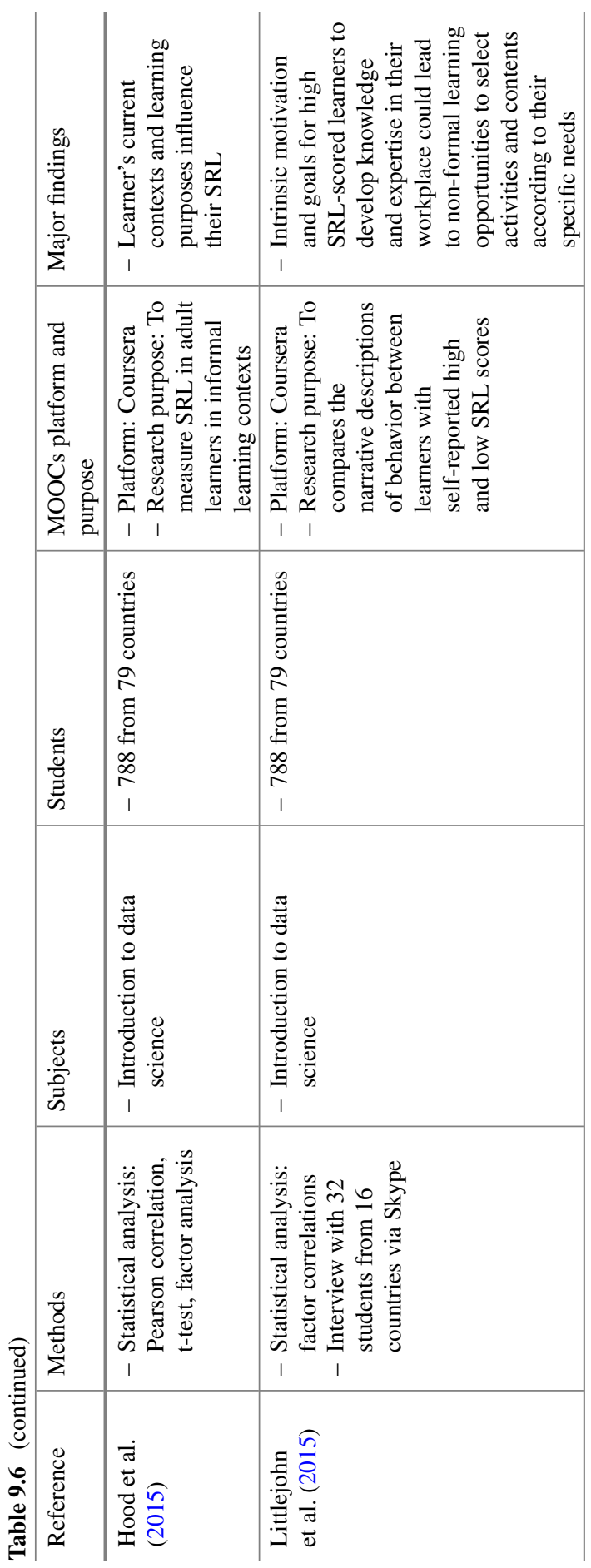


activities and contents according to their specific needs. They discussed that open, flexible, and non-linear approaches, which are different from traditional learning with a linear progression, promote SRL for highly intrinsically motivated learners. They also suggested that the completion rate of MOOCs might not be the indicator of MOOC quality and value, and new forms of evaluation criteria specific to MOOCs should be developed.

Overall, from the literature review on the third integration approach, it was found that a diverse range of students has utilized MOOCs with the purpose of informal or non-formal learning. The demographic profiles and learner behaviors in MOOCs shown in some case studies may imply that well-educated and young students consider MOOCs as a complement to traditional formal learning. However, there is still uncertainty about how MOOCs can be replacing or integrated into traditional classrooms due to the characteristics of massiveness and flexibility (Marcus-Quinn \& Clancy, 2015). Such flexible open learning contexts and massive learners have led to diverse teaching and learning paths and models. Furthermore, as MOOC platforms are rapidly growing around the world, the diversity of learners, learning objective, and learning behaviors are also getting expanded.

Due to such features, most research related to informal or non-formal learning through MOOCs was conducted with a case study method. Recent literature tends to deal with the completion and SRL problems in MOOCs (Marcus-Quinn \& Clancy, 2015). Littlejohn et al. (2015) found that one of the important purposes, why learners utilize MOOCs, is to enjoy open and flexible learning experiences. The perceived reputation and effectiveness of MOOC contents similar to the traditional learning contexts appear to make learners complete the course and increase retention (Alraimi et al. 2014; Hone \& Said, 2016). Therefore, to promote informal and nonformal learning through MOOCs, open and flexible learning experiences should be strengthened with high-quality contents.

\subsubsection{Comparison Between Integration Approaches}

Some of the previous studies compared different integration approaches. Joseph and Nath (2013) conducted a pilot study to compare formal and informal learning with MOOCs. A key difference was found in the assignment completion rate that while all participants in the formal learning group submitted at least partial assignments, only $32.5 \%$ in the informal learning group submitted partial assignments. Furthermore, $71.4 \%$ in the formal learning group accomplished the course while $7.6 \%$ in the informal learning group did. However, the number of students who received distinction was about the same: $5.7 \%$ in the formal group and $3.0 \%$ in the informal group. Gutiérrez-Santiuste, Gámiz-Sánchez, and Gutiérrez-Pérez (2015) present comparative analyzes of two integration approaches: blended learning vs. non-formal learning. First, they compared sociological, psychological, technical, and cognitive barriers that students perceived during blended learning and non-formal learning with MOOCs (see Table 9.7). It was found that the highest barrier students faced in 
Table 9.7 Satisfaction and dissatisfaction factors in MOOCs (Gutiérrez-Santiuste et al., 2015)

\begin{tabular}{l|l}
\hline Planning & $\begin{array}{l}\text { Instructional design, choice of topics, course organization, number of } \\
\text { participants, course duration }\end{array}$ \\
\hline Community & Social character, community and group work, sharing outside the platform \\
\hline Contents & Content, resources \\
\hline Technical & Technical/technological situations \\
\hline Participation & Level of involvement and contributions to the course \\
\hline
\end{tabular}

non-formal learning was technical (53\%), while students in blended learning encountered four barriers at the same level, namely $32 \%$ in technical, $28 \%$ in sociological, $20 \%$ in psychological and cognitive. Second, they compared satisfaction and dissatisfaction levels. Data indicate that $61.8 \%$ of students were satisfied with blended learning, especially in terms of planning (30.9\%), community $(16.4 \%)$, and contents $(7.3 \%)$. On the other hand, $80.1 \%$ expressed dissatisfaction, especially in terms of planning $(24.1 \%)$, evaluation $(17.8 \%)$, and contents and technical $(9.4 \%)$.

Kursun (2016) evaluated the effect of credit on learners' achievement, perceived intrinsic and extrinsic goal orientations, and perceived course value by comparing credit-bearing vs. non-credit-bearing students. While the study did not specifically focus on the integration of MOOCs, the results and implications from the study are meaningful in that the credit recognition is an important factor that universities should consider when integrating MOOCs into their traditional higher education contexts. The study found a statistically significant difference between two groups, indicating that credits influenced learner achievement, goal orientations, and perceived course values. The credit-bearing group showed significantly higher achievement scores, perceived goal orientation, and course values than the non-credit-bearing group.

Overall, comparative studies show that there are significant differences in student participation, engagement, motivation, goal orientation, course values, satisfaction, and barriers. Such findings from the comparison studies provide universities with insights on how to integrate MOOCs into own contexts. In particular, it is noteworthy that students encounter technical obstacles such as inadequate infrastructure, connection, and transmission due to the bandwidth problem, and poor functioning in online learning environments regardless of integration approaches. Universities need to deal with technical barriers when considering the integration of MOOCs into traditional offline learning. For instance, MOOC platforms should be user-friendly designed with interfaces and functions to facilitate smooth online learning experiences. A small unit of video lectures can be also considered to deal with bandwidth problems.

\subsection{Conclusion}

In this chapter, we discussed how MOOCs can be integrated in higher education, for both formal and non-formal/informal learning experiences. The development of 
large-scale MOOCs offered by elite institutions has propelled MOOCs into the mainstream. MOOCs represent the democratization of education, by making education more accessible to a wide range of learners. However, this chapter problematizes that little frameworks are available to unpack the complex potential of integrating MOOCs in higher education. With that, the integration framework proposed in this chapter considers learners' purpose (e.g., for earning academic credits) and course structure (e.g., online vs. F2F). In this chapter, we mainly discussed three possible integration approaches: (a) integrating MOOCs in blended learning, (b) integrating MOOCs in flipped learning, and (c) integrating MOOCs in non-formal/informal learning. We then discussed some related research for the respective integration approaches to provide better understandings about how MOOCs can be integrated into various contexts of higher education.

The review of related literature revealed some limitations in the existing research studies. First, authors tend to use terms loosely, such as using blended learning and flipped learning in an interchangeable way while there are clear differences between the two approaches. Second, we found that there are few empirical studies conducted on this topic, and many of them adopted a case study approach. Methodologically, there is a need to conduct more empirical studies that investigate the potential and challenges of integrating MOOCs in higher education settings. Third, we suggest that higher education institutions may need to take cautious steps in offering MOOCs to fee-paying students for academic credits. Given that the initial goal of MOOCs was to reach out to a wider range of learners, including learners in disadvantaged areas and conditions, the increasing trend of offering MOOCs to fee-paying students who are already in formal higher education may indicate that MOOCs are failing in the initial philosophy on "openness". Indeed, it is true that such features of "openness" and "free" have led MOOCs to vivid arguments of the sustainability issues including dropout rates and cost. To make MOOC platforms more sustainable, both higher education institutions and MOOCs providers need to consider some possibilities of pricing strategies (e.g., cross-subsidy, third-party, freemium and nonmonetary) in MOOC business models (Baker \& Passmore, 2016). However, MOOCs providers should also consider the balance between the original goals of MOOCs and sustainable strategies. In this respect, we believe that this chapter provides some insights concerning how MOOCs can be integrated into higher education to provide meaningful learning experiences for a wide range of learners.

\section{References}

Abdelrahman, A. M. (2016). MOOCs integration in the formal education. International Journal for Infonomics, 9(3), 1210-1216.

Akgül, Y. (2018). Accessibility evaluation of MOOCs' websites of turkey. Journal of Life Economics, 5(4), 23-36.

Alraimi, K. M., Zo, H., \& Ciganek, A. P. (2014). Understanding the MOOCs continuance: The role of openness and reputation. Computers \& Education, 80, 28-38.

Atiaja, L., \& Gueerero, R. (2016). MOOCs: Origin, characterization, principal problems and challenges in higher education. Journal of e-learning and Knowledge Society, 12(1), 65-76. 
Baker, R. M., \& Passmore, D. L. (2016). Value and pricing of MOOCs. Education Sciences, 6, 1-11. https://doi.org/10.3390/educsci6020014.

Belanger, V., \& Thornton, J. (2013). Bioelectricity: A quantitative approach - Duke University's first MOOC (Report). Retrieved from http://dukespace.lib.duke.edu/dspace/bitstream/handle/10161/ 6216/Duke_Bioelectricity_MOOC_Fall2012.pdf.

Bergmann, J., \& Sams, A. (2012) Flip your classroom: reach every student in every class every day, ISTE, ASCD. Retrieved from http://www.ascd.org/Publications/Books/Overview/ Flip-Your-Classroom.aspx.

Bergmann, J., \& Sams, A. (2014). Flipped learning: Gateway to student engagement. International Society for Technology in Education.

Bishop, J. L., \& Verleger, M. A. (2013). The flipped classroom: A survey of the research. 120th ASEE annual conference \& exposition, June 23-26.

Bralić, A., \& Divjak, B. (2016). Use of MOOCs in traditional classroom: blended learning approach. 9th research workshop, best of EDEN 2016 (pp. 47-58).

Bralić, A., \& Divjak, B. (2017). Integrating MOOCs in traditionally taught courses: achieving learning outcomes with blended learning. International Journal of Educational Technology in Higher Education, 15(2), 1-16.

Brown, M. (2018). Why invest in MOOCs? Strategic institutional drivers. In D. Jansen \& L. Konings (Eds.), The 2018 OpenupEd Trend Report on MOOCs (pp. 6-9). Maastricht, NL: EADTU. Retrieved from https://tinyurl.com/2018OpenupEdtrendreport.

Bruff, D. O., Fisher, D. H., McEwen, K. E., \& Smith, B. E. (2013). Wrapping a MOOC: Student perceptions of an experiment in blended learning. Journal of Online Learning and Teaching, 9(2), 187-199. Retrieved from https://my.vanderbilt.edu/douglasfisher/files/2013/06/ JOLTPaperFinal6-9-2013.pdf.

Bryan, A., \& Volchenkova, K. N. (2016). Blended learning: Definition, models, implications for higher education. Educational Sciences, 8(2), 24-30.

Cha, H. J., \& Park, T. J. (2019). Applying and evaluating visualization design guidelines for a MOOC dashboard to facilitate self-regulated learning based on learning analytics. KSII Transactions on Internet and Information Systems, 13(6), 2799-2823.

Chamberlin, L., \& Parish, T. (2011). MOOCs: Massive open online courses or massive and often obtuse courses? ELearn, 2011(8), 1.

Cornelius, S. (2019). Understanding learner engagement on a blended course including a MOOC. Research in Learning Technology, 27, 1-14.

Dunn, K. (2015). The challenges of launching a MOOC and reusing that material in a blended campus class. In Proceeding of 2015 Canadian Engineering Education Association (CEEA15) Conference (pp. 1-8).

European Commission. (2001). Making a European area of lifelong learning a reality (Communication from the commission). Brussels, 21.11.2001. COM(2001) 678 final. Retrieved from http:// eur-lex.europa.eu/LexUriServ/LexUriServ.do?uri=COM:2001:0678:FIN:EN:PDF.

Flipped Learning Network. (2014). The four pillars of FLIP. Retrieved from https://www.flippedpl. ca/uploads/2/3/9/6/23960677/flip_handout_fnl_web_1_.pdf.

Ghadiri, K., Qayoumi, M.H., Junn, E., Hsu, P., \& Sujitparapitaya, S. (2013). The transformative potential of blended learning using MIT edX's 6.002x online MOOC content combined with student team-based learning in class. Retrieved September 03, 2019 from https://www.edx.org/ sites/default/files/upload/ed-tech-paper.pdf.

Gillani, N., \& Eynon, R. (2014). Communication patterns in massively open online courses. Internet and Higher Education, 23, 18-26.

Graham, C. R. (2006). Blended learning systems: definition, current trends, and future directions. In Handbook of Blended Learning: Global Perspectives, Local Designs. San Francisco, CA: Pfeiffer Publishing.

Griffiths, R., Mulhern, C., Spies, R., \& Chingos, M. (2015). Adopting MOOCs on campus: A collaborative effort to test MOOCs on campuses of the university system of Maryland. Online Learning, 19(2). 
Gutiérrez-Santiuste, E., Gámiz-Sánchez, V. M., \& Gutiérrez-Pérez, J. (2015). MOOC \& B-learning: Students' barriers and satisfaction in formal and non-formal learning environments. Journal of Interactive Online Learning, 13(3), 88-111.

Halverson, A. C., \& Collins, R. (2009). Rethinking education in the age of technology. New York: Teachers College, Columbia University.

Hill, P. (2013). Emerging student patterns in MOOCs: A (revised) graphical view. Retrieved from http://mfeldstein.com/emerging-student-patterns-in-moocs-a-revised-graphical-view/.

Ho, A. D., Chuang, I., Reich, J., Coleman, C., Whitehill, J., Northcutt, C., Williams, J. J., Hansen, J., Lopez, G., \& Petersen, R. (2015). HarvardX and MITx: Two years of open online courses (HarvardX Working Paper No. 10). https://doi.org/10.2139/ssrn.2586847.

Holotescu, C., Cretu, V.I., Grosseck, G., \& Antoanela, N. (2014). Integrating MOOCs in blended courses. The 10th international scientific conference e-learning and software for education, Bucharest, April 24-25, 2014.

Hone, K. S., \& Said, G. R. (2016). Exploring the factors affecting MOOC retention: A survey study. Computers \& Education, 98, 157-168.

Hood, N., Littlejohn, A., \& Milligan, C. (2015). Context counts: How learners' contexts influence learning in a MOOC. Computers \& Education, 91, 83-91.

Hung, C. Y., Sun, J. C. Y., \& Liu, J. Y. (2018). Effects of flipped classrooms integrated with MOOCs and game-based learning on the learning motivation and outcomes of students from different backgrounds. Interactive Learning Environments, 27(8), 1028-1046. https://doi.org/10. 1080/10494820.2018.1481103.

Hwang, G. J., \& Lai, C. L. (2017). Facilitating and bridging out-of-class and in-class learning: An interactive e-Book-based flipped learning approach for math courses. Journal of Educational Technology \& Society, 20(1). Retrieved from https://www.j-ets.net/ets/journals/20_1/17.pdf.

Iniesto, F., McAndrew, P., Minocha, S., \& Coughlan, T. (2017). What are the expectations of disabled learners when participating in a MOOC? In L@S '17 Proceedings of the Fourth (2017) ACM Conference on Learning (pp. 225-228). New York, NY: ACM.

Jordan, K. (2014). Initial trends in enrolment and completion of massive open online courses. The International Review of Research in Open and Distributed Learning, 15(1). https://doi.org/10. 19173/irrodl.v15i1.1651.

Joseph, A. I. M., \& Nath, B. A. (2013). Integration of Massive Open Online Education (MOOC) system with in-classroom interaction and assessment and accreditation: An extensive report from a pilot study. Kolkata: Department of Computer Science, St. Xavier's College (Autonomous).

Kaltencker, N., Huesig, S., Hess, T., \& Dowling, M. (2013). The disruptive potential of software as a service: validation and application of an ex-ante methodology. Thirty-fourth international conference on information systems, Milan, Italy.

Kirschner, P. A., Sweller, J., \& Clark, R. E. (2006). Why minimal guidance during instruction does not work: An analysis of the failure of constructivist, discovery, problem-based, experiential, and inquiry-based teaching. Educational Psychologist, 41(2), 75-86.

Kuhn, D. (2007). Is direct instruction an answer to the right question? Educational Psychologist, 42(2), 109-113.

Kursun, E. (2016). Does formal credit work for MOOC-like learning environments? International Review of Research in Open and Distributed Learning, 17(3), 77-91.

Lapworth, A. (2018). Trends towards a sustainable MOOC platform. In D. Jansen, \& L. Konings (Eds.), The 2018 OpenupEd Trend Report on MOOCs (pp. 6-9). Maastricht, NL: EADTU. Retrieved from https://tinyurl.com/2018OpenupEdtrendreport.

Littlejohn, A., Hood, N., Milligan, C., \& Mustain, P. (2015). Learning in MOOCs: motivations and self-regulated learning in MOOCs. Internet and Higher Education, 29, 40-48.

Littlejohn, A., \& Milligan, C. (2015). Designing MOOCs for professional learners: Tools and patterns to encourage self-regulated learning. eLearning, 42(4), 1-10.

Marcus-Quinn, A., \& Clancy, I. (2015). Learning objects in MOOC: Good practice for learning object. In M. Anabela \& P. Paula (Eds.), Furthering higher education possibilities through Massive Open Online Courses (pp. 150-164). Hershey, PA: IGI Global. 
Morris, N. P. (2014). How digital technologies, blended learning and MOOCs will impact the future of higher education. International Conference e-Learning, 2014, 401-404.

National Research Council. (2012). Discipline-based education research: Understanding and improving learning in undergraduate science and education. Washington, DC, WA: National Academies Press.

OECD (2010). Recognition of non-formal and informal learning. Retrieved from http://www.oecd. org/education/skills-beyond-school/recognitionofnon-formalandinformallearning-home.htm.

Perna, L. W., Ruby, A., Boruch, R. F., Wang, N., Scull, J., \& Ahmad, S. (2014). Moving through MOOCs: understanding the progression of users in massive open online courses. Educational Researcher, 43(9), 421-432.

Sandeen, C. (2013). Integrating MOOCs into traditional higher education: The emerging "MOOC 3.0" era. Change: The Magazine of Higher Learning, 45(6), 34-39.

Sfiri, A., Pietkiewicz, K., \& Jansen, D. (2016). Existing MOOC initiatives in higher education and business sector and the distribution of MOOC learners in EU28. BizMOOC Discussion Paper. Retrieved from https://bizmooc.eu/papers/initiatives/?print=print.

Sharpe, R., Benfield, G., Roberts, G., \& Francis, R. (2006). The undergraduate experience of blended e-learning: a review of UK literature and practice. York, UK: The Higher Education Academy.

Strayer, J. F. (2012). How learning in an inverted classroom influences cooperation, innovation and task orientation. Learning Environments Research, 15(2), 171-193.

Thai, N. T. T., De Wever, B., \& Valcke, M. (2017). The impact of a flipped classroom design on learning performance in higher education: Looking for the best "blend" of lectures and guiding questions with feedback. Computers \& Education, 107, 113-126.

Tucker, B. (2012). The flipped classroom: Online instruction at home frees class time for learning, Education Next, Winter 2012. Retrieved from http://www.msuedtechsandbox.com/MAETELy22015/wp-content/uploads/2015/07/the_flipped_classroom_article_2.pdf.

Weller, M. (2014). Characteristics and completion rates of distributed and centralized MOOCs project details. MOOC Research Initiative. Retrieved from http://www.moocresearch.com/ wpcontent/uploads/2014/06/C9131_WELLER_MOOC-Research-Initiative-OU.pdf.

Hyunjin Cha is an Assistant Professor in the College of Hyangseol Nanum, SoonChunHyang University in Korea. She obtained a M.Sc. in Human-Computer Interaction with Ergonomics from University College London, and a Ph.D. in Educational Technology from Hanyang University, Seoul, Korea. Her current research areas include user-friendly teaching and learning environments and User Experiences (UX) in education as well as Universal design for learning. Previously, she worked for KERIS, Korea Education and Research Information Service, an affiliated organization of ministry of education in Korea. She has conducted several research projects on ICT in Education indicators with UNESCO Institute of Statistics (UIS) and ICT for Educational Development (ICT4ED).

Hyo-Jeong So is a Full Professor in the Department of Educational Technology, Ewha Womans University in Korea. Previously, she was with Pohang University of Science and Technology (POSTECH), Korea and National Institute of Education, Nanyang Technological University, Singapore. She received her Ph.D. degree from Instructional Systems Technology, Indiana University. Her main research interests include mobile learning, Computer-Supported Collaborative Learning (CSCL), and informal learning. She is particularly interested in examining how to integrate emerging technologies for teaching and learning from collaborative knowledge building perspectives. She has conducted several research projects on emerging technologies in education funded by Microsoft, Korean National Research Foundation, and IDRC, Canada. In addition, she has published several research papers in the international journals and working paper series with UNESCO. 
Open Access This chapter is licensed under the terms of the Creative Commons Attribution 4.0 International License (http://creativecommons.org/licenses/by/4.0/), which permits use, sharing, adaptation, distribution and reproduction in any medium or format, as long as you give appropriate credit to the original author(s) and the source, provide a link to the Creative Commons license and indicate if changes were made.

The images or other third party material in this chapter are included in the chapter's Creative Commons license, unless indicated otherwise in a credit line to the material. If material is not included in the chapter's Creative Commons license and your intended use is not permitted by statutory regulation or exceeds the permitted use, you will need to obtain permission directly from the copyright holder.

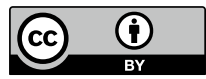

